\title{
Marine Biodiversity
}

\section{Basal monothalamous and pseudochambered benthic foraminifera associated with planktonic foraminiferal shells and mineral grains from the Porcupine Abyssal Plain, NE \\ Atlantic \\ --Manuscript Draft--}

\begin{tabular}{|l|l|}
\hline Manuscript Number: & MARB-D-14-00083R1 \\
\hline Full Title: & $\begin{array}{l}\text { Basal monothalamous and pseudochambered } \\
\text { planktonic foraminiferal shells and mineral grain } \\
\text { Atlantic }\end{array}$ \\
\hline Article Type: & S.I.: Meioscool \\
\hline Corresponding Author: & $\begin{array}{l}\text { Paris Vasileios Stefanoudis, MSc } \\
\text { National Oceanography Centre } \\
\text { Southampton, Hampshire UNITED KINGDOM }\end{array}$ \\
\hline
\end{tabular}

Corresponding Author Secondary

Information:

Corresponding Author's Institution:

National Oceanography Centre

Corresponding Author's Secondary

Institution:

First Author:

Paris Vasileios Stefanoudis, MSc

First Author Secondary Information:

Order of Authors:

Paris Vasileios Stefanoudis, MSc

Andrew J Gooday, Ph.D.

Order of Authors Secondary Information:

Abstract:

We present a survey of 'live' (stained) and dead monothalamous (single-chambered, mainly spherical) and pseudochambered (chain-like) foraminifera associated with planktonic foraminiferal shells and mineral grains, based on two samples from one abyssal plain site ( $\mathrm{F} 2,4,880 \mathrm{~m}$ water depth) and one abyssal hill site $(\mathrm{H} 4,4,330 \mathrm{~m}$ water depth) on the Porcupine Abyssal Plain (PAP), northeast Atlantic. Our study is the first to focus on this poorly known component of abyssal foraminiferal faunas and highlight their abundances and diversity at the PAP. In both samples these monothalamids and pseudochambered forms represented $27-35 \%$ and $18-23 \%$, respectively, of the entire 'live' and dead foraminiferal assemblage (>150 $\mu \mathrm{m}, 0-1 \mathrm{~cm}$ sediment layer). Among 1078 stained and dead specimens we recognize a total of 18 distinct morphotypes on the basis of test characteristics. Another 144 specimens could not be assigned to any morphotype and are regarded as indeterminate. Most of the monothalamids are small $(<150 \mu \mathrm{m})$, although some incorporate planktonic foraminiferal shells to create larger structures. In absolute terms, stained and dead individuals of these morphotypes were more abundant at the abyssal hill site although data from additional samples are needed to confirm if this is representative of differences between abyssal hills and the surrounding abyssal plain at the PAP. Agglutinated spheres and domes similar to some of our abyssal forms have been reported from shelf and slope settings, but they are generally much larger. Small agglutinated spheres are very common in the abyssal Pacific, at depths close to or below the carbonate compensation depth (CCD). However, they are composed largely of siliceous particles, including mineral grains, radiolarians and diatom fragments. In contrast, carbonate oozes at the PAP, situated above the CCD, are rich in coccoliths and planktonic foraminiferal shells, which are used in the construction of agglutinated spheres and domes. Our results underline the important contribution made by largely underestimated foraminiferal taxa to abyssal communities.

Response to Reviewers:

'see attachment' 
1 Basal monothalamous and pseudochambered benthic

2 foraminifera associated with planktonic foraminiferal shells

3 and mineral grains from the Porcupine Abyssal Plain, NE

4 Atlantic

5

6 Paris V. Stefanoudis •Andrew J. Gooday

7

8

9

10

11

12

13

14

15

16

17

18

19

20

21

22

23

24

25

26

27 Paris V. Stefanoudis $(\bowtie) \cdot$ Andrew J. Gooday

28 Ocean Biogeochemistry and Ecosystems (DEEPSEAS Group), National Oceanography

29 Centre, University of Southampton Waterfront Campus, European Way, Southampton 30 SO14 3ZH, UK

31 e-mail: p.v.stefanoudis@ soton.ac.uk 
32 Abstract We present a survey of 'live' (stained) and dead monothalamous (single33 chambered, mainly spherical) and pseudochambered (chain-like) foraminifera 34 associated with planktonic foraminiferal shells and mineral grains, based on two samples from one abyssal plain site (F2, 4,880 m water depth) and one abyssal hill site 36

Keywords Single-chambered monothalamids $\cdot$ Pseudochambered foraminifera •

61

62 Our study is the first to focus on this poorly known component of abyssal foraminiferal faunas and highlight their abundances and diversity at the PAP. In both samples these monothalamids and pseudochambered forms represented $27-35 \%$ and 18-23\%, respectively, of the entire 'live' and dead foraminiferal assemblage ( $>150 \mu \mathrm{m}, 0-1 \mathrm{~cm}$ sediment layer). Among 1078 stained and dead specimens we recognize a total of 18 distinct morphotypes on the basis of test characteristics. Another 144 specimens could not be assigned to any morphotype and are regarded as indeterminate. Most of the monothalamids are small $(<150 \mu \mathrm{m})$, although some incorporate planktonic foraminiferal shells to create larger structures. In absolute terms, stained and dead individuals of these morphotypes were more abundant at the abyssal hill site although data from additional samples are needed to confirm if this is representative of differences between abyssal hills and the surrounding abyssal plain at the PAP. Agglutinated spheres and domes similar to some of our abyssal forms have been reported from shelf and slope settings, but they are generally much larger. Small agglutinated spheres are very common in the abyssal Pacific, at depths close to or below the carbonate compensation depth (CCD). However, they are composed largely of siliceous particles, including mineral grains, radiolarians and diatom fragments. In contrast, carbonate oozes at the PAP, situated above the CCD, are rich in coccoliths and planktonic foraminiferal shells, which are used in the construction of agglutinated spheres and domes. Our results underline the important contribution made by largely underestimated foraminiferal taxa to abyssal communities. 


\section{Introduction}

Benthic foraminifera are one the of most abundant and species-rich groups in the deep sea, often accounting $>50 \%$ of the meiofauna (Snider et al. 1984; Gooday 2014) and in some areas a large proportion of the macrofauna (Tendal and Hessler 1977). Diversity and distributional patterns of hard-shelled calcareous and robustly agglutinated forms (mainly multichambered) have been widely documented (Murray 1991; Gooday and Jorissen 2012; Murray 2013), but relatively little is known about organic-walled and delicately agglutinated, predominantly monothalamous (single-chambered) species, hereafter termed monothalamids (Pawlowski et al. 2013). Due to their fragile nature these taxa have a poor fossil record (Tappan and Loeblich 1988; Mackensen et al. 1990) resulting in an incomplete picture of past foraminiferal communities. In modern oceans these delicate species can constitute a dominant element of deep-sea foraminiferal assemblages (Tendal and Hessler 1977; Bernstein et al. 1978; Snider et al. 1984; Nozawa et al. 2006), particularly at abyssal plains below the carbonate compensation depth (CCD) (Schröder et al. 1988).

Monothalamids encompass a wide variety of organic-walled and agglutinated taxa with spherical, flask-shaped, tubular or more complex test morphologies and in some cases a soft, flexible test wall. Their internal structure is relatively simple and deep-sea species often contain masses of waste pellets, termed stercomata. They represent the basal radiation of foraminifera that gave rise to morphologically diverse groups of multichambered calcareous and agglutinated forms (Pawlowski et al. 2003; Pawlowski et al. 2013). Monothalamids are generally poorly known and usually overlooked in faunal studies of the deep-sea benthos. Many species are undescribed and their often simple morphologies, which lack prominent features, make their identification problematic. Nevertheless, monothalamids are a highly diverse group, often constituting $>30 \%$ of the total foraminiferal species pool and are thought to represent a significant undocumented source of biodiversity on the ocean floor (Gooday et al. 2004; Enge et al. 2012). Recently developed molecular techniques, including ultra-deep sequencing of foraminiferal microbarcodes in environmental DNA samples, have emphasized their dominance $(>80 \%)$ in deep-sea foraminiferal assemblages (Lecroq et al. 2011). 
124 Two core samples $\left(25.5 \mathrm{~cm}^{2}\right.$ surface area) were collected during R.S.S. James Cook 125 Cruise 062 (JC062) (July-August 2011) at an abyssal plain site (F2; station JC062-77, $1264,818 \mathrm{~m}$ water depth) and a somewhat shallower, abyssal hill site (H4; station JC062127 126, 4,330 m water depth) within the area of the PAP (Fig. 1; Table 1). Onboard the 
128 ship, the cores were sliced into layers down to 10-cm depth and each slice fixed in $10 \%$ 129 buffered formalin. The present work, which is part of a larger study of foraminifera 130 from the PAP, is based on the $0-1 \mathrm{~cm}$ sediment layer.

131 In the laboratory, the $0-0.5 \mathrm{~cm}$ and $0.5-1.0 \mathrm{~cm}$ slices of cores from the F2 and $132 \mathrm{H} 4$ sites, were gently washed through two sieves (mesh sizes: $300 \mu \mathrm{m}$ and $150 \mu \mathrm{m}$ ) 133 using filtered tap water. Residues $>300 \mu \mathrm{m}$ and 150-300 $\mu \mathrm{m}$ were stained with Rose 134 Bengal (1 $\mathrm{g}$ dissolved in $1 \mathrm{~L}$ of tap water) overnight and sorted for all 'live' (stained) 135 and dead foraminifera in water in a Petrie dish under a binocular microscope. In order to 136 ensure that the stained material was foraminiferal protoplasm, specimens were 137 transferred to glass slides with glycerine and examined under a high power compound 138 microscope. Delicate taxa were either stored on glass cavity slides in glycerol or in 2-ml 139 Nalgene cryovials in $10 \%$ buffered formalin.

140 The specimens considered in the present paper were informally assigned to 141 morphotypes (morphologically similar specimens) on the basis of test morphology and 142 wall structure.

144 Light and scanning electron microscopy

146 Specimens placed in water in a glass cavity slide were photographed using a NIKON 147 Coolpix 4500 camera mounted on an Olympus SZX10 compound microscope. Selected 148 specimens were dried onto aluminium scanning electron microscopy (SEM) stubs, gold 149 sputter coated and subsequently examined by SEM using a LEO 1450VP (variable 150 pressure) scanning electron microscope.

\section{Results}

154 Entire benthic foraminiferal assemblages

156 Densities for the entire 'live' assemblage (i.e. all foraminiferal taxa, multichambered as 157 well as monothalamids, in the 150-300 and $>300 \mu \mathrm{m}$ combined) were 49 individuals. 10 $158 \mathrm{~cm}^{-2}$ at the abyssal plain site (F2) and 84 indiv. $10 \mathrm{~cm}^{-2}$ at the abyssal hill site (H4). The 159 corresponding values for the entire dead assemblages were 611 indiv. $10 \mathrm{~cm}^{-2}$ (F2) and 
1601206 indiv.10 $\mathrm{cm}^{-2}$ (H4). For the monothalamids and pseudochambered forms 161 considered here, 42 'live' individuals ( 16.5 indiv. $\left.10 \mathrm{~cm}^{-2}\right)$ were counted at the abyssal 162 plain site (F2) and 59 'live' individuals ( 23.1 indiv. $10 \mathrm{~cm}^{-2}$ ) at the abyssal hill site (H4). 163 The corresponding values for the dead assemblages were 356 individuals (139.3 164 indiv. $10 \mathrm{~cm}^{-2}$ ) (F2) and 567 individuals (222.2 indiv. $10 \mathrm{~cm}^{-2}$ ) (H4). The majority of the 165 specimens ('live' and dead) in both sites were concentrated in the $0-0.5 \mathrm{~cm}$ (Table 2). 166 In both samples these two groups represented 27-35\% and 18-23\% of the 'live' and 167 dead fauna respectively (Table 2). In the case of an additional 42 (F2) and 156 (H4) 168 individuals it was impossible to determine using Rose Bengal staining if they were 169 'live' or dead. These ?live specimens represented $10 \%$ and $20 \%$ of the total number of 170 monothalamids and pseudochambered forms found at the abyssal plain and abyssal hill 171 site respectively (Table 2).

172

173 Diversity of monothalamous and pseudochambered foraminifera

174

175 Overall, we recognized a total of 18 distinct forms among 1078 monothalamous and 176 pseudochambered foraminifera picked from the samples at the two sites (Table 3). None

177 can be placed in a described species. We regard them as morphotypes although those 178 with consistent, well-defined morphologies are probably distinct species. A further 144 179 monothalamous specimens could not be assigned to any morphotype and were regarded 180 indeterminate. They will not be considered further.

Monothalamids attached to or lodged between planktonic foraminiferal shells 183

184 The majority (11) of the 18 forms are soft spheres that are sessile on a planktonic 185 foraminiferal shell or are lodged between two or more planktonic shells. These 186 monothalamous foraminifera exhibit a wide morphological diversity and contain some 187 of the most abundant forms (Table 3). They include the following types.

1. Thin-walled sphere (Figs. 2a-b; Type 1 in Table 3). A thin-walled 189 agglutinated sphere $(<150 \mu \mathrm{m}$ in maximum dimension) containing stercomata usually confined between several (>2) planktonic shells. 
2. Sphere with long flimsy tubes (Figs. 2c-e; Type 2 in Table 3). Easily recognizable and abundant form with one or more long flimsy tubes extending out of 193 the main, approximately spherical, test. In some cases the tubes are 2 to 3 times the 194 length of the main test, which is between $100-150 \mu \mathrm{m}$ in maximum dimension. The 195 specimens are attached to one or more planktonic shells and occasionally incorporate 196 small quartz grains, in which case the specimens are somewhat larger (approx. $200 \mu \mathrm{m}$ ) 197 (Fig. 2c).

3. Dome with cap attached to large planktonic foraminiferal shell (Figs. 2f-h; Type 3 in Table 3). A small dome (approx. $100 \mu \mathrm{m}$ ) attached to a large planktonic shell on one side and capped by a much smaller shell on the other side. This simple type is very common in both sites (Table 3). The wall is mainly composed of coccoliths (Fig. $2 h)$.

4. Delicate thick-walled sphere with red-stained interior (Figs. 3a-e; Type 4 in Table 3). Agglutinated spherical test with red-stained protoplasm, containing sparse stercomata. It usually forms a large structure $>300 \mu \mathrm{m}$ due to the incorporation of several large planktonic shells, although the sphere itself is never more than $100 \mu \mathrm{m}$ in diameter. The test has a thick wall and is commonly exposed on one end (i.e. not covered by planktonic shells). A typical feature is the presence of one or more round openings on the exposed surface through which the red-stained test interior is visible. These openings are encircled by a slightly raised rim (Figs. 3a-c) and appear to be a natural feature rather than the result of damage to the test wall. When dried on a SEM stub, the sphere shrinks and the openings deform, indicating that the wall is flexible to some degree (Figs. 3d-e).

5. Round, slightly opaque sphere with red-stained interior (Figs. 3f-h; Type 5 in Table 3). Round agglutinated sphere (approx. $200 \mu \mathrm{m}$ diameter) with a few attached planktonic shells. The agglutinated material of the test comprises a mixture of coccoliths and small mineral grains, in many cases plate-like, giving the sphere a slightly reflective and opaque appearance. The interior contains stercomata but these cannot be seen clearly through the wall.

6. Crithionina-like sphere (Figs. 3i-k; Type 6 in Table 3). A distinctive form with a thick white test made of finely agglutinated particles (mainly coccoliths). These 
222 specimens resemble the well-known agglutinated genus Crithionina, although they are much smaller $(<150 \mu \mathrm{m})$ than any described species of the genus.

7. 'Classic dome' (Figs. 4a-d; Type 7 in Table 3). Small (approx. $100 \mu \mathrm{m}$ diameter), more or less spherical agglutinated sphere on top of a large planktonic shell, with many smaller shells incorporated into the test, occasionally also mineral grains. It contains numerous stercomata, which makes it difficult to distinguish 'live' from dead individuals. This monothalamid is termed 'classic dome', and is by far the most abundant morphotype at both sites.

8. Sphere with short tube (Figs. 4e-f; Type 8 in Table 3). Monothalamous morphotype incorporating planktonic shells and similar in appearance to the 'classic dome'. It differs in that the test gives rise to a short tube, rarely longer than the main test (100-150 $\mu \mathrm{m}$ diameter). SEM images reveal coccoliths as the main agglutinated constituent for both the test and the tube.

9. Red sphere with stercomata, between planktonic shells (Figs. 5a-e; Type 9 in Table 3). An agglutinated, more or less spherical test (approx. $100 \mu \mathrm{m}$ diameter) attached to planktonic shells to form a much larger, irregular-shaped structure. In most specimens some shells have to be removed in order to reveal the sphere (Figs. 5b-c). As the sphere contains numerous large stercomata, stained individuals have a dark red color. When dried on the SEM stub the sphere shrinks, but stercomata are still clearly visible (Fig. 5e).

10. Thin-walled red sphere attached to large planktonic shell (Figs 5f-g; Type 10 in Table 3). Agglutinated sphere $(100-150 \mu \mathrm{m}$ diameter) attached to a large planktonic shell and incorporating smaller shells in its test. This form resembles "classic dome', but has a thinner wall and specimens are always brightly stained, suggesting that stercomata are absent or sparse.

11. Soft sphere lodged between two planktonic shells (Fig. 5h; Type 11 in Table 3). Finely agglutinated sphere with flexible wall and smooth surface, lodged between two large planktonic shells. The test (approx. $100 \mu \mathrm{m}$ in maximum dimension) of the single specimen incorporates tiny planktonic shells, imparting a whitish/grey color when viewed under the stereomicroscope. The faded grey color suggests that the protoplasm contains stercomata. 


\section{Monothalamids associated with mineral grains}

255

256 12. Monothalamids associated with mineral grains (Figs. 6a-c; Type 12 in Table 3). 257 The foraminiferans in this category are small, spherical or domed monothalamids that 258 use mineral grains to construct their test. The grains comprise a variety of whitish, 259 yellow and orange particles, some of them plate-like, thus often resembling the 260 agglutinated genus Psammosphaera. They are found either free-living, with maximum 261 dimension up to $150 \mu \mathrm{m}$, or attached to planktonic foraminiferal shells and/or quartz 262 grains, to form much larger structures. The spheres and domes included in this category 263 are difficult to separate into distinct morphotypes.

264

265

266

267 The following tubular morphotypes are associated with planktonic shells.

13. Spherical chamber with tubes (Figs. 6d-f; Type 13 in Table 3). This form comprises a small (approx. $50 \mu \mathrm{m}$ diameter), spherical, agglutinated chamber that gives rise to two narrow rigid tubes (each approximately $100 \mu \mathrm{m}$ long and $15 \mu \mathrm{m}$ diameter) from opposite ends of its test, although only the base of one tube is present in the figured specimen. Large coccoliths are the main agglutinated particle.

14. Short, soft-walled tube (Figs. 6g-i; Type 14 in Table 14). A short $(<150 \mu \mathrm{m})$ curved, soft-walled tube, open at both ends and apparently complete, sitting on top of a planktonic foraminiferal shell.

\section{Pseudochambered (chain-like) forms}

A number of forms have tests comprising a series of swellings or chamber-like segments (regarded as pseudochambers), which are sessile on, or surrounded by, planktonic foraminiferal shells. We recognize four forms based on the number of pseudochambers and planktonic shells involved, and the presence/absence of stercomata. 15. Double dome (Figs. 7a-c; Type 15 in Table 3). Two more or less spherical domes attached to a planktonic shell, each approximately $100 \mu \mathrm{m}$ long, linked by a 
285 short "bridge" and containing dark stercomata. Both domes are composed of small planktonic shells set in a matrix of coccoliths.

16. Pseudochambers linked with stolons (Figs. 7d-f; Type 16 in Table 3).

288 Domed pseudochambers (approx. $100 \mu \mathrm{m}$ diameter) associated with planktonic shells containing dark stercomata and linked by narrow stolons made of coccoliths. In some cases the stolons are open at one end (Fig. 7f). This morphotype resembles "double dome" but the pseudochambers are flatter and shrink when dried on a SEM stub.

17. Chain with thick tube (Figs. 7g-i; Type 17 in Table 3) Two pseudochambers (approx. 50 and $100 \mu \mathrm{m}$ long) connected by a relatively thick tube and attached to two large planktonic shells. The entire structure (pseudochambers and tube) is about $300 \mu \mathrm{m}$ long. The wall is composed of coccoliths and mineral grains imparting a shiny appearance under the stereomicroscope.

\section{Indeterminate chain of chambers (Figs. 7j-1; Type 18 in Table 3). Complex} chains comprising several pseudochambers of variable size that incorporate small planktonic foraminiferal shells, extending across one or more large planktonic shells and connected with narrow stolons. The incorporation of planktonic shells makes the arrangement of the pseudochambers and the relationship between them very difficult to decipher.

Occurrence at abyssal hill and abyssal plain sites

Our examination of the two samples suggests some differences in the contribution of morphotypes between the abyssal hill and abyssal plain sites. However, analyses of additional replicates will be necessary to confirm these patterns. In absolute terms, monothalamid and pseudochambered foraminifera were more abundant at the abyssal hill site (H4) compared to the abyssal plain site (F2), for both the 'live' (23 vs. 17 indiv. $10 \mathrm{~cm}^{-2}$ ) and the dead fauna (222 vs. 140 indiv.10 $\mathrm{cm}^{-2}$ ) (see Table 2). Most morphotypes, including the three most abundant ones (Types 2-3, 7 in Table 3), had comparable relative abundances (i.e. percentage of the total number of monothalamids) at both sites, but there were some exceptions. Monothalamids with test composed of mineral grains (Type 12 in Table 3) were found almost exclusively at the abyssal hill site while delicate thick-walled spheres with red stained interior (Type 4 in Table 3) 
317 were only encountered on the abyssal plain site. Moreover, spheres with short tube 318 (Type 8 in Table 3) were more abundant at the abyssal hill site while pseudochambered 319 forms (Types 15-18, Table 3) were more abundant at the abyssal plain site. Some 320 monothalamids (Types 13-14 in Table 3) and pseudochambered forms (Types 15, 17 in 321 Table 3) were confined either to the abyssal hill or abyssal plain site, but as they were 322 all uncommon, and in some cases were singletons, little can be concluded regarding 323 their distribution.

\section{Discussion}

\section{Limitations of dataset}

Because of their delicate nature, the foraminifera described here might be vulnerable to mechanical damage, particularly during the sieving of sediment samples. Those particularly prone to breakage would include chain-like forms in which the segments are joined by fragile stolons that often span more than one planktonic shell (Fig. 7). The sieving process was carried out as gently as possible and most of the specimens that we examined appeared to be intact. It is possible that the 'spheres with long flimsy tubes' (Figs. 2c-e) represent fragments of chain-like formations in which the tubes link together several chambers, although we have no direct evidence for this interpretation.

The recognition of 'live' individuals was sometimes problematic, particularly in the case of forms in which the test contents were dominated by stercomata, for example the 'classic dome' (Fig. 4a; Type 7 in Table 3). Another problem in some forms was that the central chamber was obscured by planktonic shells, which had to be removed in order to reveal whether or not the contents were stained (e.g. Figs. 5a-c; Type 9 in Table 3). This procedure both damages the specimen and is time-consuming. Because of these problems, the numbers of 'live' specimens may have been underestimated. Because the present analysis was confined to the $0-1 \mathrm{~cm}$ sediment layer, further staining of deeper layers is necessary to examine if these foraminifera live at greater depths within the sediment. Moreover, as this study was based on only two samples, replicates are needed in order to confirm the differences between the abyssal hill and abyssal plain sites. 
Comparison with other studies

\section{Continental margin monothalamids}

354 There are certain similarities between the abyssal morphotypes considered here and 355 monothalamous foraminifera illustrated in earlier publications. In particular 356 monothalamids associated with mineral grains resemble some illustrations of 357 Psammosphaera fusca from the North Sea (Heron-Allen and Earland 1913; e.g. Plate II 358 figs. 3.10-3.12). Here, specimens of $P$. fusca used a variety of particles to construct 359 their tests, mainly mineral grains but also dead foraminiferal shells. Heron-Allen and 360 Earland (1913) reported both free-living and sessile forms of this species, the latter 361 attached to sponge spicules, larger foraminiferal tests and molluscan shells. These 362 authors also recorded Crithinonina mamilla, which was found on similar substrates. 363 This species resembles our Crithinionia-like sphere in having a white thick-walled test. 364 However, P. fusca and C. mamilla were reported from shelf and slope settings (16$3651,600 \mathrm{~m}$ ) rather than abyssal depths and were much larger (approx. 550-1,150 $\mu \mathrm{m}$ ) than 366 our morphotypes, which in most cases did not exceed $150 \mu \mathrm{m}$. Differences in food 367 supply linked to differences in depth probably explain their larger size.

Abyssal environments: differences between Pacific and Atlantic monothalamids

371 Snider et al. (1984) analysed box-core samples taken at 5,800 m depth in the North 372 Pacific in order to assess the composition and distribution of the meio- and nanofauna. 373 They found that an important part of the abundance and biomass of benthic foraminifera 374 comprised small $(<100 \mu \mathrm{m}$ diameter $)$ 'sac-shaped' individuals, which they called 375 Crithionina. These were presumably some sorts of agglutinated spheres. In the Kaplan 376 East area of the abyssal eastern Equatorial Pacific, Nozawa et al. (2006) reported tiny 377 free-living agglutinated spheres termed 'indeterminate psammosphaerids' that were 378 consistently more abundant (usually $60-80 \%$ of the total 'live' assemblage) than other 379 foraminifera. A small $(<100 \mu \mathrm{m}$ diameter) agglutinated spherical form was described 380 from the Kaplan Central site by Ohkawara et al. (2009) as Saccammina minimus. This 
381 species incorporated radiolarian tests and shard-like diatom fragments in its test and contained stercomata.

The abundance of small agglutinated spheres at abyssal sites in both the Pacific

401 Topographic high points can generate distinctive environmental conditions. Thistle et 402 al. (1999) reported faunal and ecological differences between high points (seamounts) 403 and flat areas. High points tend to have stronger currents (Roden 1987) and coarser 404 sediment (Levin and Thomas 1989). Our abyssal hill site resembles a small seamount 405 (see Fig. 1; Table 1). Thus, we would expect stronger currents and coarser sediment 406 compared to the abyssal plain site, which might affect the abundance and species 407 composition of sediment-dwelling fauna (Kaufmann et al. 1989; Levin et al. 1994) 408 including the foraminifera (Kaminski 1985). Our observations suggest that this is true 409 for monothalamous and pseudochambered foraminifera, as their densities are greater at 410 the abyssal hill site. Furthermore, monothalamids that incorporate mineral grains as part 411 of their test are almost exclusively restricted to this elevated setting where larger quartz 412 grains are available. Taking into account the patchy distribution of benthic foraminifera 
413 in abyssal environments (Bernstein and Meador 1979), replicate samples will clearly be 414 necessary to confirm this pattern. However, if confirmed, this would have implications 415 for the role of abyssal hills in generating faunal heterogeneity.

\section{Concluding remarks}

419 Our preliminary study provides evidence for the prevalence of certain types of basal 420 ('primitive') foraminifera at the PAP area of the northeast Atlantic. They represent a 421 subset of the diverse and largely undescribed monothalamids that flourish in the deep sea and represent an important component of abyssal benthic communities. The forms

423 that we describe are all associated with planktonic foraminiferal shells, an important 424 component of the sand fraction of sediments at the PAP, which is situated above the 425 CCD. In the abyssal Pacific, where the CCD is shallower, radiolarian tests take the 426 place of planktonic foraminifera as sand-sized components of the sediment. Currently, 427 there are many problems associated with the study of these abyssal monothalamids, 428 among them, distinguishing 'live' from dead individuals and obtaining molecular genetic data in order to address their phylogenetic relationships. These remain important challenges for the future.

The fossil record of monothalamous foraminifera is generally poor (Tappan and Loeblich, 1988). Some apparently delicate agglutinated species have been found in ancient marine sediments (e.g., Nestell and Tolmacheva 2004; Nestell et al., 2009) and agglutinated tests that resemble testate amoebae are known from Neoproterozoic sediments (Porter and Knoll, 2000). We are not aware of any forms in the fossil record similar to those described here, although it is possible that they may be discovered eventually in Late Cretaceous sediments deposited in the North Atlantic and Western Tethys (now Western Mediterranean) Oceans, in some cases above the CCD. These sediments have yielded diverse deep-water agglutinated foraminiferal assemblages (e.g., 444 
445 Acknowledgements We thank the captain and the crew of the R.S.S. James Cook and the scientists 446 participating in James Cook cruise 062 for their assistance with the field operations. We are very grateful 447 to the Meioscool organizers Daniela Zeppilli and Aurelie Francois and all the other anonymous helpers 448 for the very successful workshop in Brest, France $\left(26^{\text {th }}-29^{\text {th }}\right.$ November $)$ and to Dr Zeppilli for her 449 invitation to contribute to the Meioscool special issue of Marine Biodiversity. We also thank Dr Kirsty 450 Morris for kindly helping us with preparing Fig. 1, and two anonymous reviewers for their comments, 451 which helped to improve the manuscript. One of us (PVS) is jointly funded by NERC and the School of 452 Ocean and Earth Sciences, University of Southampton. This research contributes to the NERC-funded 453 efforts of the Autonomous Ecological Survey of the Abyss project (AESA, Henry Ruhl, Principal 454 Investigator) and the Porcupine Abyssal Plain - Sustained Observatory.

455

456

457

458

459

460

461

462

463

464

465

466

467

468

469

470

471

472

473

474

475

476

477

478

479

480

481

482

483 


\section{References}

485

Berger WH (1978) Sedimentation of deep-sea carbonate; maps and models of variations and fluctuations. J Foramin Res 8:286-302

Bernstein BB, Hessler RR, Smith R, Jumars PA (1978) Spatial dispersion of benthic Foraminifera in abyssal central North Pacific. Limnol Oceanogr 23:401-416

Bernstein BB, Meador JP (1979) Temporal persistence of biological patch structure in an abyssal benthic community. Mar Biol 51:179-183 doi:Doi 10.1007/Bf00555197

Biscaye PE, Kolla V, Turekian KK (1976) Distribution of calcium carbonate in surface sediments of the Atlantic Ocean. J Geophys Res 81:2595-2603 doi:Doi 10.1029/Jc081i015p02595

Earland A (1933) Foraminifera. Part II. South Georgia. Discovery Rep 7:27-138

Earland A (1934) Foraminifera. Part III. The Falklands sector of the Antarctic (excluding South Georgia). Discovery Rep 10:1-208, pls.201-210

Earland A (1936) Foraminifera. Part IV. Additional records from the Weddel Sea sector from material obtained by the S.Y. 'Scotia'. Discovery Rep 10:1-76

Enge AJ, Kucera M, Heinz P (2012) Diversity and microhabitats of living benthic foraminifera in the abyssal Northeast Pacific. Mar Micropaleontol 96-97:84-104 doi:Doi 10.1016/J.Marmicro.2012.08.004

Gooday AJ, Carstens M, Thiel H (1995) Microforaminifera and nanoforaminifera from abyssal northeast Atlantic sediments: a preliminary report. Int Rev Ges Hydrobio 80:361-383 doi:Doi 10.1002/Iroh.19950800223

Gooday AJ, Hori S, Todo Y, Okamoto T, Kitazato H, Sabbatini A (2004) Soft-walled, monothalamous benthic foraminiferans in the Pacific, Indian and Atlantic Oceans: aspects of biodiversity and biogeography. Deep-Sea Res Pt I 51:33-53 doi:Doi 10.1016/J.Dsr.2003.07.002

Gooday AJ, Malzone MG, Bett BJ, Lamont PA (2010) Decadal-scale changes in shallow-infaunal foraminiferal assemblages at the Porcupine Abyssal Plain, NE Atlantic. Deep-Sea Res Pt II 57:1362-1382

Gooday AJ, Jorissen FJ (2012) Benthic foraminiferal biogeography: controls on global distribution patterns in deep-water settings. Annu Rev Mar Sci 4:237-262 doi:Doi 10.1146/Annurev-Marine120709-142737

Gooday AJ (2014) Deep-sea benthic foraminifera. Earth Systems and Environmental Sciences:1-20. http://dx.doi.org/10.1016/B978-0-12-409548-9.09071-0. Accessed 29 May 2014

Heron-Allen E, Earland A (1913) On some foraminifera from the North Sea, etc, dredged by the Fisheries cruiser 'Goldseeker' (International North Sea Investigations - Scotland). II. On the distribution of Saccammina sphaerica (M. Sars) and Psammosphaera fusca (Schulze) in the North Sea: particularly with reference to the sugested identity of the two species. J R Microsc Soc:1-26

Heron-Allen E, Earland A (1932) The ice-free area of the Falkland Islands and adjacent seas. Discovery Rep 4:291-460 
522 Kaminski MA (1985) Evidence for control of abyssal agglutinated foraminiferal community structure by substrate disturbance - results from the Hebble Area. Mar Geol 66:113-131 doi:Doi $10.1016 / 0025-3227(85) 90025-8$

Kaufmann RS, Wakefield WW, Genin A (1989) Distribution of epibenthic megafauna and lebensspuren on two central North Pacific seamounts. Deep-Sea Res Pt I 36:1863-1896 doi:Doi 10.1016/0198-0149(89)90116-7

Kuhnt W, Kaminski M (1989) Upper Cretaceous deep-water agglutinated benthic foraminiferal assemblages from the Western Mediterranean and adjacent areas. In: Wiedmann J (ed) Cretaceous of the Western Tethys. Proceedings of the Third International Cretaceous Symposium, Tübingen, Scheizerbart'sche Verlagsbuchhandlung, Stuttgart, pp 91-120

Kuhnt W, Kaminski MA, Moullade M (1989) Late Cretaceous deep-water agglutinated foraminiferal assemblages from the North Atlantic and its marginal seas. Geol Rundsch 78:1121-1140

Lecroq B et al. (2011) Ultra-deep sequencing of foraminiferal microbarcodes unveils hidden richness of early monothalamous lineages in deep-sea sediments. P Natl Acad Sci USA 108:13177-13182 doi:Doi 10.1073/Pnas.1018426108

Levin LA, Thomas CL (1989) The influence of hydrodynamic regime on infaunal assemblages inhabiting carbonate sediments on central Pacific seamounts. Deep-Sea Res Pt I 36:1897-1915 doi:Doi 10.1016/0198-0149(89)90117-9

Levin LA, Leithold EL, Gross TF, Huggett CL, Dibacco C (1994) Contrasting effects of substrate mobility on infaunal assemblages inhabiting two high-energy settings on Fieberling Guyot. J Mar Res 52:489-522 doi:Doi 10.1357/0022240943077028

Loeblich AR, Tappan H (1987) Foraminiferal genera and their classification. Van Nostrand Reinhold, New York

Mackensen A, Grobe H, Kuhn G (1990) Benthic foraminiferal assemblages from the eastern Weddell Sea between 68 and $73 \mathrm{~S}$ : distribution, ecology and fossilization potential. Mar Micropaleontol $16: 241-283$

Mikhalevich VI (2005) Polymerization and oligomerization in foraminiferal evolution. Stud Geol Polon 124:117-141

Murray JW (1991) Ecology and palaeoecology of benthic foraminifera. Longman Scientific \& Technical, New York

Murray JW (2013) Living benthic foraminifera: biogeographical distributions and the significance of rare morphospecies. J Micropalaeontol 32:1-58

Nestell GP, Tolmacheva TY (2004) Early Ordovician foraminifers from the Lava Section, northwestern Russia. Micropaleontol 50:253-280

Nestell GP, Mestre A, Heredia S (2009) First Ordovician foraminifera from South America: a Darriwilian (Middle Ordovician) fauna from the San Juan Formation, Argentina. Micropaleontol 55:329-344

Nozawa F, Kitazato H, Tsuchiya M, Gooday AJ (2006) 'Live' benthic foraminifera at an abyssal site in the equatorial Pacific nodule province: Abundance, diversity and taxonomic composition. DeepSea Res Pt I 53:1406-1422 doi:Doi 10.1016/J.Dsr.2006.06.001 
561 Ohkawara N, Kitazato H, Uematsu K, Gooday AJ (2009) A minute new species of Saccammina (monothalamous Foraminifera; Protista) from the abyssal Pacific. J Micropalaeontol 28:143-151 doi:Doi 10.1144/Jm.28.2.143

564 Pawlowski J et al. (2003) The evolution of early Foraminifera. P Natl Acad Sci 30:11494-11498

565 Pawlowski J, Holzmann M, Tyszka J (2013) New supraordinal classification of Foraminifera: molecules meet morphology. Mar Micropaleontol 100:1-10 doi:Doi 10.1016/J.Marmicro.2013.04.002

567 Porter SM, Knoll AH (2000) Testate amoebae in the Neoproterozoic Era: evidence from vase-shaped microfossils in the Chuar Group, Grand Canyon. Paleobiol 26: 360-385

569 Roden GI (1987) Effects of seamounts and seamount chains on ocean circulation and thermohaline structure. In: Keating BH, Fryer P, Batiza R, Boehlert GW (eds) Seamounts, Islands and Atolls. American Geophysical Union, Washington, D. C, pp 335-354

Schröder CJ, Scott DB, Medioli FS, Bernstein BB, Hessler RR (1988) Larger agglutinated Foraminifera: comparison of assemblages from central North Pacific and Western North Atlantic (Nares Abyssal Plain). J Foramin Res 18:25-41

Snider LJ, Burnett BR, Hessler RR (1984) The composition and distribution of meiofauna and nanobiota in a central North Pacific deep-sea area. Deep-Sea Res Pt I 31:1225-1249 doi:Doi 10.1016/0198-0149(84)90059-1

Tappan H, Loeblich AR (1988) Foraminiferal evolution, diversification, and extinction. J Paleontol 62:695-714

Tendal OS, Hessler RR (1977) An introduction to the biology and systematics of Komokiacea (Textulariina, Foraminiferida). Galathea Rep 14:165-194

585

586

587

588

589

590

591

592

593

594

595

596 


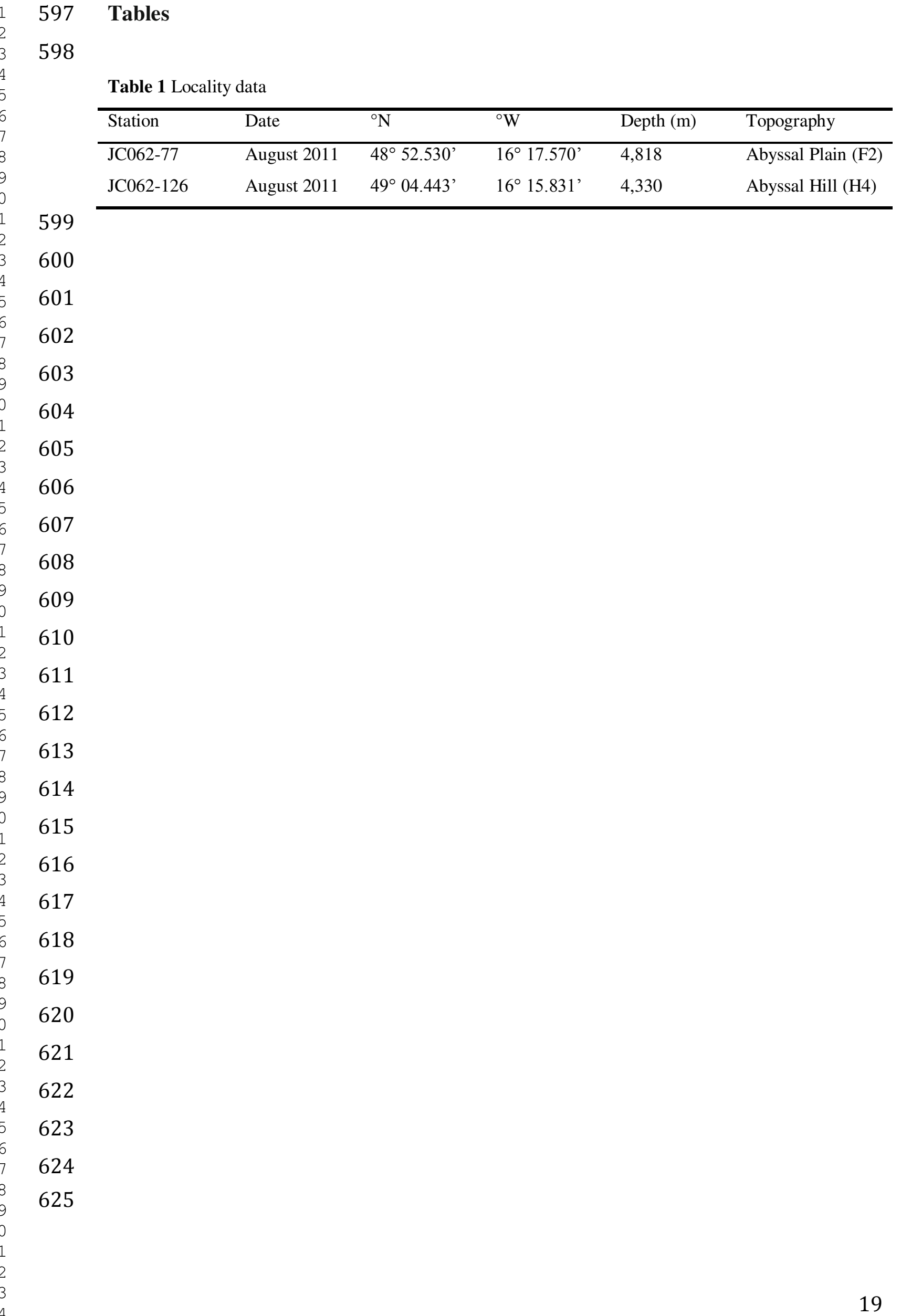


Table 2 Counts $(\mathrm{N})$ of monothalamid and pseudochambered morphotypes, including fragments and indeterminate specimens, from the $0-0.5 \mathrm{~cm}$ and $0.5-1 \mathrm{~cm}$ sediment layers. Densities (individuals per 10 $\mathrm{cm}^{2}$ ) are shown in brackets after the counts per sample. Also shown are their relative abundance (\%) amongst the entire 'live' (stained) and dead assemblage (multichambered and monothalamid taxa) from the two samples $(>150-\mu \mathrm{m}$ fraction) for the two layers combined (i.e. $0-1 \mathrm{~cm}$ ). The percentages for the ?live category represent their proportion among the total number of monothalamids and pseudochambered morphotypes present in the $0-1 \mathrm{~cm}$. SL = sediment layer, $\mathrm{F} 2=$ abyssal plain, $\mathrm{H} 4=$ abyssal hill

\begin{tabular}{|c|c|c|c|c|c|c|c|c|c|}
\hline \multirow{3}{*}{$\begin{array}{l}\text { SL } \\
(\mathrm{cm})\end{array}$} & \multicolumn{3}{|c|}{ 'Live' (stained) } & \multicolumn{3}{|c|}{ Dead } & \multicolumn{3}{|c|}{ ?Live } \\
\hline & \multicolumn{2}{|c|}{$\mathrm{N}$} & \multirow{2}{*}{$\begin{array}{r}\% \\
0-1\end{array}$} & \multicolumn{2}{|c|}{$\mathrm{N}$} & \multirow{2}{*}{$\begin{array}{l}\% \\
0-1\end{array}$} & \multicolumn{2}{|c|}{$\mathrm{N}$} & \multirow{2}{*}{$\begin{array}{l}\% \\
0-1\end{array}$} \\
\hline & $0-0.5$ & $0.5-1$ & & $0-0.5$ & $0.5-1$ & & $0-0.5$ & $0.5-1$ & \\
\hline \multirow[t]{2}{*}{$\mathrm{F} 2$} & 29 & 13 & 34.7 & 340 & 16 & 22.9 & 22 & 20 & 9.6 \\
\hline & (11.4) & $(5.1)$ & & (133) & $(6.3)$ & & (8.6) & $(7.8)$ & \\
\hline \multirow[t]{2}{*}{$\mathrm{H} 4$} & $46(18)$ & 13 & 27.4 & 434 & 133 & 18.4 & 17 & 139 & 19.9 \\
\hline & & $(5.1)$ & & $(170)$ & $(52.2)$ & & $(6.7)$ & $(54.5)$ & \\
\hline
\end{tabular}

627

628

629

630

631

632

633

634

635

636

637

638

639

640

641

642

643 
Table 3 Occurrence of monothalamid and pseudochambered morphotypes associated with planktonic foraminiferal shells and mineral grains in PAP samples ( $>150-\mu \mathrm{m}$ fraction). L = 'live' (stained), D = dead. The numbers in the left-hand column correspond to those in the text

\begin{tabular}{|c|c|c|c|}
\hline Morphotypes & Figure & F2 (abyssal plain) & H4 (abyssal hill) \\
\hline & & ?live & $\mathrm{L}$ \\
\hline
\end{tabular}

Monothalamids attached to or lodged

between planktonic foraminiferal shells

1) Thin-walled sphere

2) Sphere with long flimsy tubes

3) Dome with cap attached to large planktonic foraminiferal shell

4) Delicate thick-walled sphere with redstained interior

5) Round, slightly opaque sphere with red-stained interior

6) Crithionina-like sphere

7) 'Classic dome'

8) Sphere with short tube

9) Red sphere with stercomata, between planktonic shells

10) Thin-walled red sphere attached to large planktonic shell

11) Soft sphere lodged between two planktonic shells

Monothalamids associated with mineral grains

12) Monothalamids associated with mineral grains

Monothalamids associated with tubes

13) Spherical chamber with tubes

14) Short, soft-walled tube

Pseudochambered (chain-like) forms

15) Double dome

16) Pseudochambers linked with stolons

17) Chain with thick tube

18) Indeterminate chain of chambers

$\begin{array}{lllllll}\text { 2a,b } & 0 & 0 & 3 & 2 & 0 & 0 \\ \text { 2c,d,e } & 3 & 78 & 8 & 7 & 113 & 1 \\ & & & & & & \\ \text { 2f,g,h } & 1 & 34 & 0 & 7 & 55 & 0\end{array}$

$\begin{array}{lllllll}3 \mathrm{a}, \mathrm{b}, \mathrm{c}, \mathrm{d}, \mathrm{e} & 9 & 0 & 0 & 0 & 0 & 0\end{array}$

$\begin{array}{lllllll}3 \mathrm{f}, \mathrm{g}, \mathrm{h} & 1 & 0 & 0 & 1 & 0 & 0\end{array}$

$\begin{array}{lllllll}3 \mathrm{i}, \mathrm{j}, \mathrm{k} & 0 & 5 & 0 & 1 & 7 & 1\end{array}$

$\begin{array}{lllllll}4 \mathrm{a}, \mathrm{b}, \mathrm{c}, \mathrm{d} & 19 & 155 & 12 & 30 & 271 & 25\end{array}$

$\begin{array}{lllllll}4 \mathrm{e}, \mathrm{f} & 1 & 2 & 0 & 3 & 29 & 0\end{array}$

$\begin{array}{lllllll}\text { 5a,b,c,d,e } & 5 & 9 & 0 & 5 & 2 & 3\end{array}$

$\begin{array}{lllllll}5 f, g & 1 & 0 & 0 & 3 & 0 & 1\end{array}$

$5 \mathrm{~h}$

$\begin{array}{llllll}2 & 0 & 0 & 0 & 4 & 0\end{array}$

$\begin{array}{lllllll}6 \mathrm{~d}, \mathrm{e}, \mathrm{f} & 0 & 0 & 0 & 0 & 8 & 0 \\ 6 \mathrm{~g}, \mathrm{~h}, \mathrm{i} & 0 & 0 & 0 & 0 & 1 & 0\end{array}$

$\begin{array}{lllllll}7 \mathrm{a}, \mathrm{b}, \mathrm{c} & 0 & 0 & 0 & 0 & 4 & 0\end{array}$

$\begin{array}{lllllll}7 \mathrm{~d}, \mathrm{e}, \mathrm{f} & 0 & 15 & 0 & 0 & 9 & 0\end{array}$

$\begin{array}{lllllll}7 \mathrm{~g}, \mathrm{~h}, \mathrm{i} & 0 & 1 & 0 & 0 & 0 & 0\end{array}$

$\begin{array}{lllllll}7 \mathrm{j}, \mathrm{k}, \mathrm{l} & 0 & 53 & 0 & 0 & 4 & 0\end{array}$

$\begin{array}{llllll}42 & 356 & 23 & 59 & 567 & 31\end{array}$




\section{Figures}

648 Fig. 1 Bathymetry map of the PAP area showing the positions of our two study sites, F2 (abyssal plain 649 site) and $\mathrm{H} 4$ (abyssal hill site), in relation to the PAP central site, which is the focus of long-term time650 series sampling at the Porcupine Abyssal Plain Sustained Observatory (e.g. Gooday et al., 2010)

Fig. 2 Monothalamids attached to, or lodged between, planktonic foraminiferal shells. Reflected light 654 655 images (a, c, d, f); SEM images (b, e, g, h). Thin-walled sphere (a, b). Sphere with long flimsy tubes (ce). Dome with cap attached to large planktonic foraminiferal shell ( $\mathbf{f}-\mathbf{h})$

Fig. 3 Monothalamids attached to, or lodged between, planktonic foraminiferal shells. Reflected light images (a-c, f, i); SEM images (d, e, $\mathbf{g}, \mathbf{h}, \mathbf{j}, \mathbf{k})$. Delicate thick-walled spheres with red stained interior (a-c); SEM images of the third (c) specimen (d, e). Round, slightly opaque sphere with red stained interior (f-h). Crithionina-like sphere (i-k)

Fig. 4 Monothalamids attached to, or lodged between, planktonic foraminiferal shells. Reflected light images $(\mathbf{a}, \mathbf{b}, \mathbf{e})$; SEM images $(\mathbf{c}, \mathbf{d}, \mathbf{f})$. 'Classic dome' $(\mathbf{a}-\mathbf{d})$. Sphere with short tube $(\mathbf{e}, \mathbf{f})$

Fig. 5 Monothalamids attached to, or lodged between, planktonic foraminiferal shells. Reflected light images (a-c, f-h); SEM images (d, e). Red sphere with stercomata, between planktonic shells (a-e). Thin-walled red sphere attached to large planktonic shell (f, g). Soft sphere lodged between two planktonic shells (h)

Fig. 6 Monothalamid associated with mineral grains and tubes. Reflected light images (a, d, g); SEM images $(\mathbf{b}, \mathbf{c}, \mathbf{e}, \mathbf{f}, \mathbf{h}, \mathbf{i})$. Monothalamids utilizing yellow, orange and transparent mineral grains for constructing their test (a); SEM images of a specimen attached to a planktonic shell (b) and a free-living form $(\mathbf{c})$. Spherical chamber with tubes $(\mathbf{d}-\mathbf{f})$. Short, soft-walled tube $(\mathbf{g}-\mathbf{i})$

Fig. 7 Pseudochambered (chain-like) morphotypes. Reflected light images (a, b, d, e, g, j-l); SEM images $(\mathbf{c}, \mathbf{f}, \mathbf{h}, \mathbf{i})$. Double dome $(\mathbf{a}-\mathbf{c})$. Pseudochambers linked with stolons $(\mathbf{d}-\mathbf{f})$. Chain with thick tube $(\mathbf{g}-\mathbf{i})$. Indeterminate chain of chambers $(\mathbf{j}-\mathbf{l})$ 


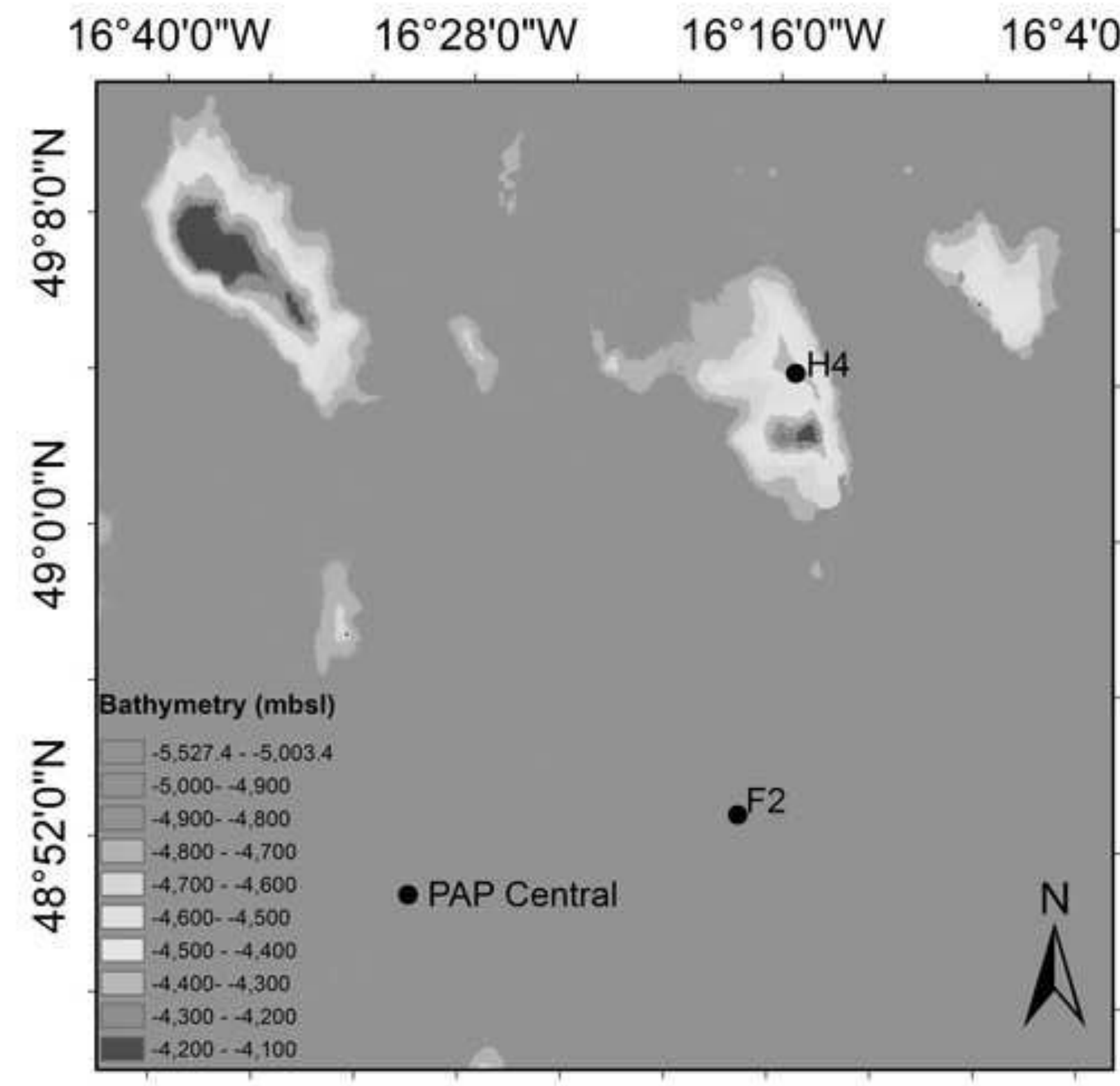




\section{Figure}

Click here to download high resolution image

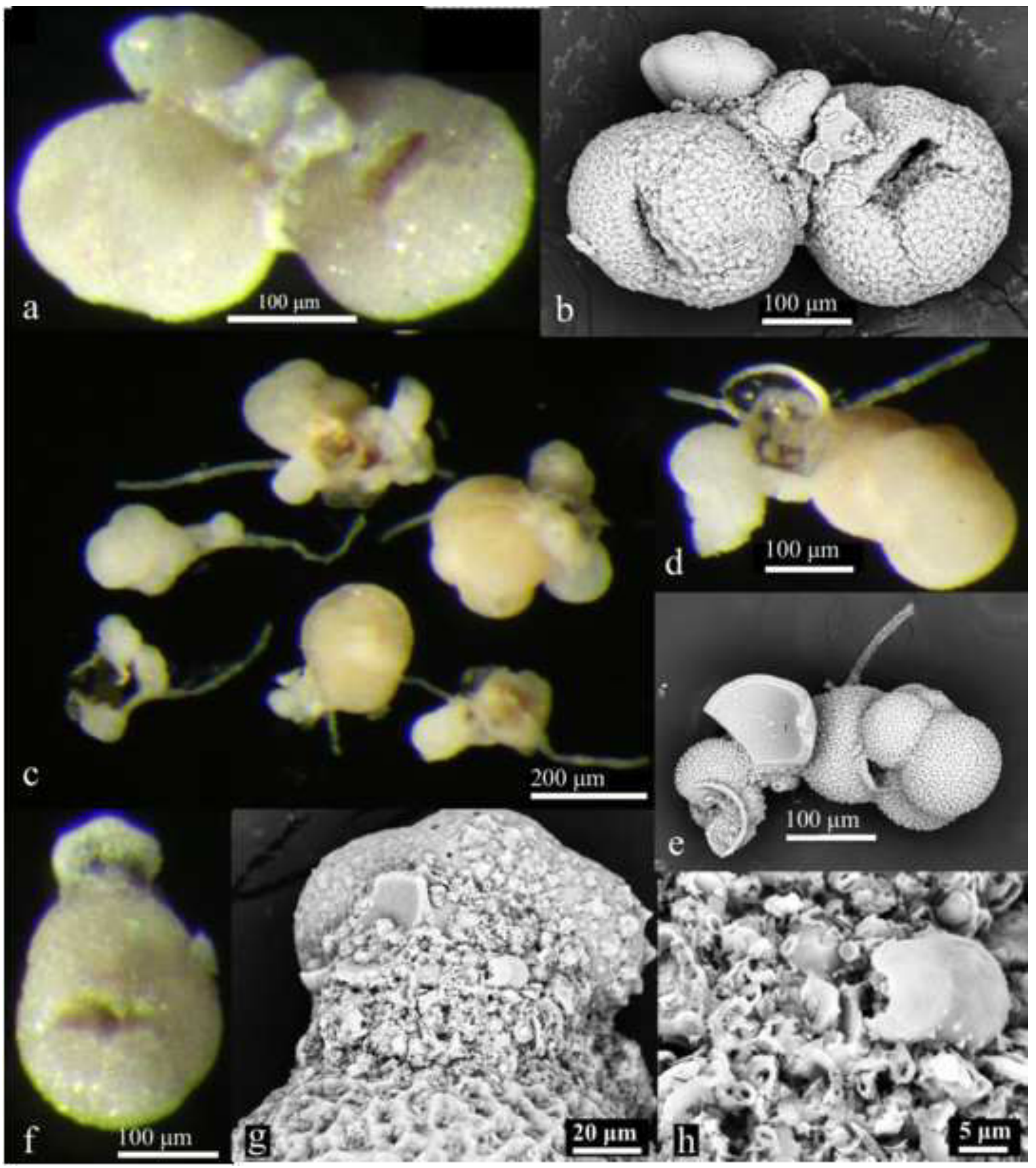




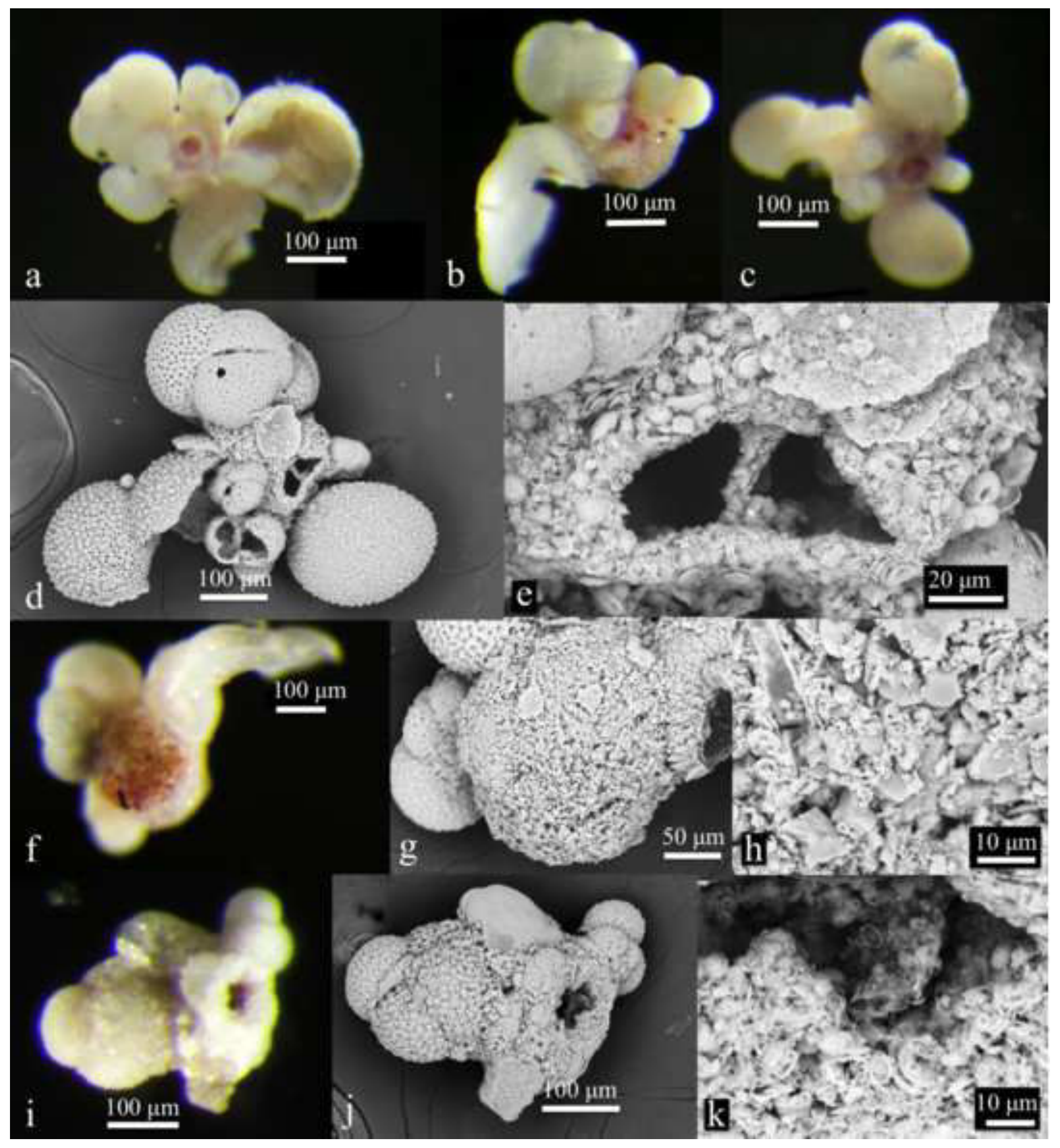




\section{Figure 4}

Click here to download high resolution image
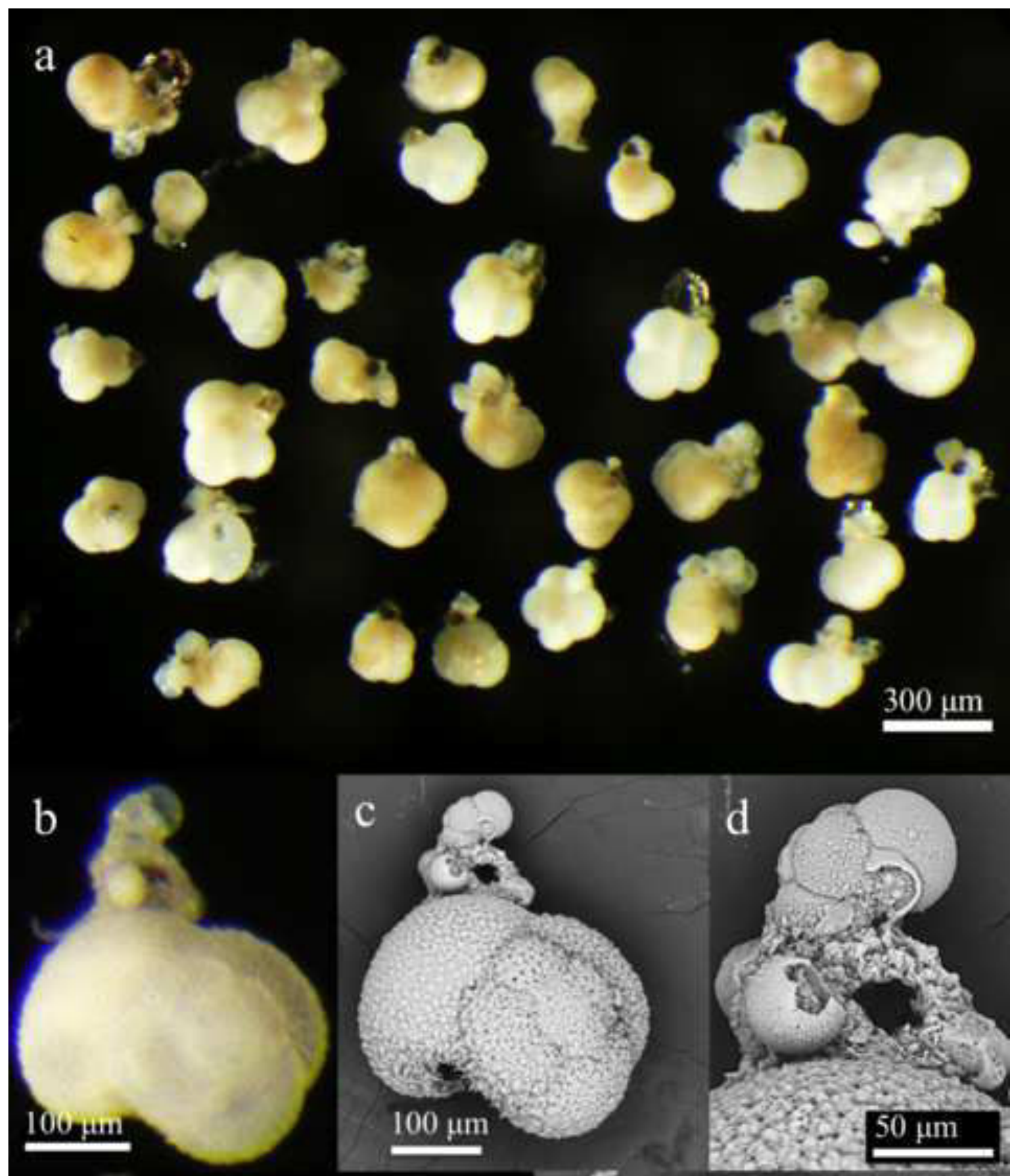

e
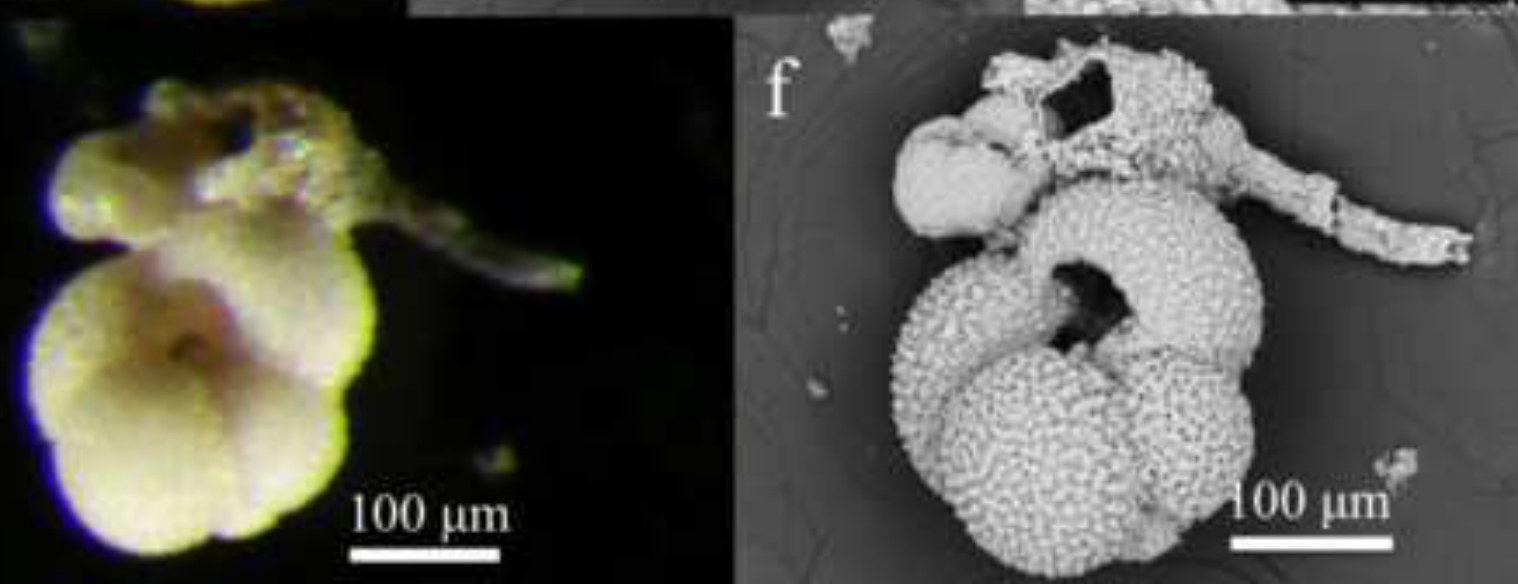
Figure 5
Click here to download high resolution image

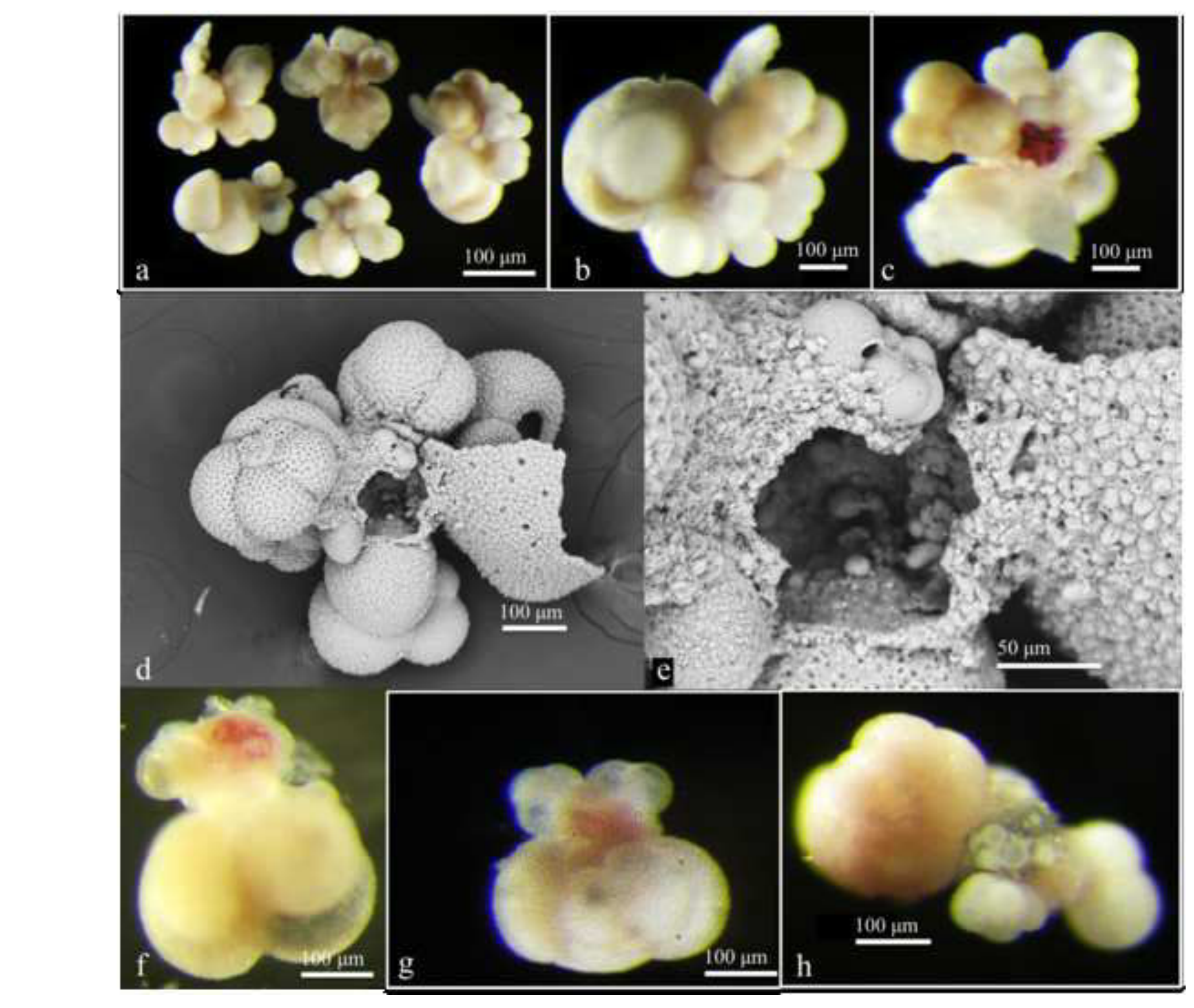




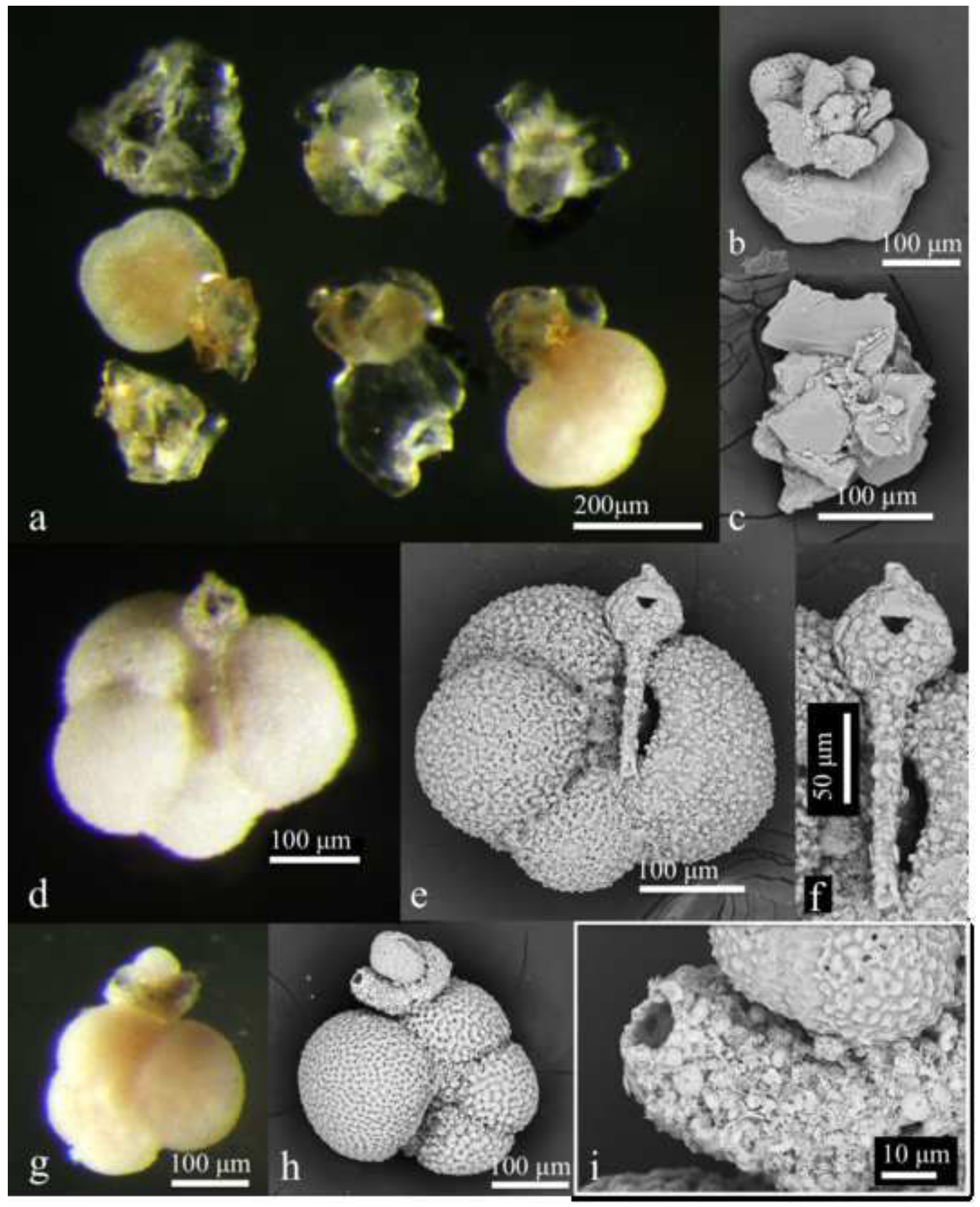


Click here to download high resolution image

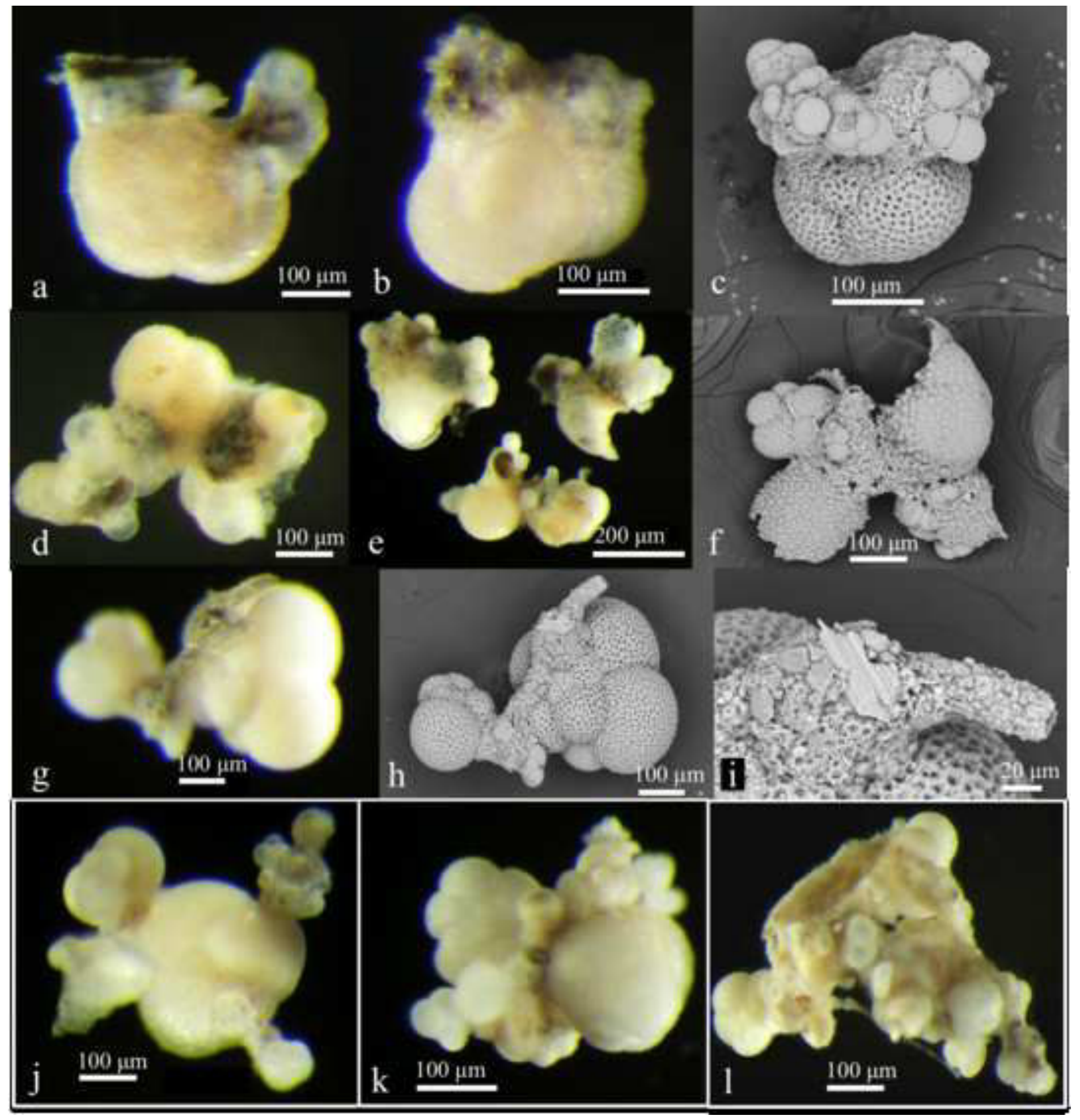

